\title{
Indígenas na cidade de Manaus (AM)
}

\section{Indigenous people in the city of Manaus (AM)}

José Carlos Matos Pereira - Doutor em Ciências Sociais, pela Universidade do Estado do Rio de Janeiro (UERJ). Pesquisador do Programa de Memória dos Movimentos Sociais, Colégio Brasileiro de Altos Estudos (CBAE/UFRJ).E-mail: jcpmatos@gmail.com

\section{Resumo}

Neste artigo tratamos dos mecanismos sociais que permitem aos indígenas manterem os laços sistemáticos com a aldeia e a afirmação de sua identidade étnica na cidade. Preservar aspectos do modo de vida apreendido na aldeia como o uso da língua e dos rituais; a socialização dos filhos com as narrativas e as danças; fazer o artesanato; praticar os hábitos alimentares; receber os parentes vindos para a cidade e manter contato sistemático com aqueles que ainda moram na aldeia são indicadores do pertencimento étnico - o que implica na organização indígena em torno das associações étnicas, multiétnicas e de gênero e na luta por políticas diferenciadas no contexto urbano. Estas situações contradizem o suposto desaparecimento indígena dos cômputos populacionais e revelam, em contrapartida, a necessidade de políticas públicas tomando por base suas reivindicações identitárias. São aspectos relevantes da análise das múltiplas etnias que vivem na cidade de Manaus (AM), na Amazônia brasileira.

\section{Palavra-chave}

Amazônia Indígena. Cidade e Identidade Indígena. Políticas Diferenciadas. Multiétnico.

\begin{abstract}
This paper addresses the social mechanisms that allow indigenous peoples to keep systematic ties with their villages and to assert their ethnic identity in the city. It studies aspects of life from the village which are preserved: the use of language and rituals; familiarizing children with narratives and dances; making crafts; playing and eating habits; welcoming relatives to the city and maintaining systematic contact with kinsfolk who still live in the village, all of which are indicators of ethnic belonging - which implies the indigenous organization around ethnic, multi-ethnic and gender issues associations and the struggle for differentiated policies in the urban context. These situations contradict the alleged disappearance of the indigenous population and data reveals, however, the need for public policy, based on their identity empowerment. These are important aspects of the analysis of multiple ethnic groups living in the city of Manaus (AM), in the Brazilian Amazon.
\end{abstract}

\section{Keywords}

Indigenous Amazon. City and Indigenous Identity. Differentiated Policies. Multiethnic. 


\section{INTRODUÇÃO}

A narrativa hegemônica sobre o nascimento do Brasil apresenta a chegada dos portugueses em Porto Seguro, costa sul da Bahia, no século XVI. Este lugar tem grande significação no imaginário coletivo por representar o marco zero do nascimento e informa a percepção das crianças, de portadores de conhecimento especializado e da opinião pública sobre o mito do "descobrimento" e traz em seu teor o essencialismo e a depreciação dos povos indígenas, tidos como atores secundários, o que politicamente anula a sua importância na formação social brasileira (PACHECO DE OLIVEIRA, 2016). Essa é a narrativa contada segundo a lógica dominante que omite conflitos, assassinatos, resistências e antagonismos à ordem social vigente no período.

Passados mais de 500 anos, do tão falado "descobrimento", podemos apresentar outra possibilidade interpretativa dos fatos a partir de situações que ocorrem com indígenas em cidades brasileiras, que serão aqui representadas por Manaus, capital do estado do Amazonas, na Amazônia brasileira.

Lembramos que em estudo clássico sobre os indígenas Terêna nas cidades de Campo Grande, Aquidauana e Miranda, hoje estado do Mato Grosso do Sul, Oliveira (1968) assinala que o indígena vai para a cidade e leva consigo um pouco da aldeia. Identificando em suas análises a manutenção das relações de parentesco, dos vínculos com a aldeia e as afirmações identitárias para indígenas que passam pelo processo de urbanização.

Mais recentemente, os dados do Censo Indígena 2010 (IBGE, 2010a) indicam que, dos 817.963 indígenas autodeclarados do Brasil, 315 mil de 300 etnias já vivem em cidades brasileiras e, em especial, em todas as capitais e em todos os estratos de cidades e regiões, perfazendo $36,2 \%$ do total dos indígenas do país. Essa presença se soma à efervescência das lutas identitárias em que múltiplas etnias protagonizam ações para se fazerem conhecer e serem reconhecidas como portadoras de direitos e de políticas diferenciadas, que precisam ser implementadas por diferentes instâncias de governo.

Isso guarda relação com o artigo aqui apresentado, no qual indagamos quem são os indígenas, onde moram e trabalham, quais são as suas principais dificuldades, como se organizam politicamente, quais são as suas demandas e proposições na cidade e que relações mantêm com a aldeia, de forma a propiciar reflexões acerca desses sujeitos demandantes do reconhecimento étnico. 


\title{
1 PRESENÇA INDÍGENA MULTIÉTNICA NA CIDADE DE MANAUS ${ }^{1}$
}

\author{
Temos o direito de ser iguais quando a diferença \\ nos inferioriza e a ser diferentes quando a \\ igualdade nos descaracteriza. \\ Boaventura de Sousa Santos (2002, p. 75)
}

Manaus é a cidade mais populosa da Amazônia brasileira com quase 2 milhões de habitantes (IBGE, 2010b), distribuídos em 63 bairros por uma área

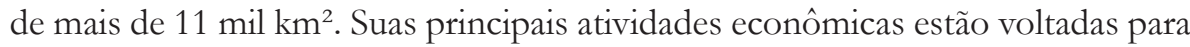
a indústria por conta da Zona Franca de Manaus, além do comércio e serviços e do turismo internacional. Mas o que nos chama especialmente a atenção é a diversidade étnica nesta metrópole. Os dados do Censo 2010 (IBGE, 2010b) apresentam 4.020 indígenas autodeclarados, representando 92 etnias, que falam 36 diferentes línguas ${ }^{2}$ distribuídos em 62 bairros. Já os dados do Censo 2000 quantificaram em, aproximadamente, 8 mil indígenas autodeclarados ${ }^{3} \mathrm{e}$ as organizações indígenas fazem referência a 20 mil indígenas.

Baines (2001) levanta dúvidas quanto ao uso de dados censitários para tratar da questão dos indígenas em cidades, já que a negação da própria identidade se constitui em uma estratégia para fugir do preconceito e estigma, o que causaria subnotificação da autoidentificação e, consequentemente, o baixo quantitativo populacional demonstrado pelos números. Ao contrário disso, a Coordenação das Organizações Indígenas da Amazônia Brasileira (COIAB) estima entre 15 e 20 mil os indígenas na cidade de Manaus. Soma-se a essas situações o desconhecimento de muitos indígenas e famílias da etnia à qual pertencem, embora se assumam como indígenas.

Diante do desencontro das informações e da necessidade de conhecer a realidade local, optamos, como metodologia de pesquisa, por visitar os bairros onde se localizam as organizações indígenas e conversar com lideranças, realizar

1 Este artigo é resultado de nossa pesquisa sobre indígenas em cidades amazônicas, onde estudamos os casos das cidades de Altamira, no Pará, e Manaus e São Gabriel da Cachoeira, no Amazonas, durante o pós-doutorado no Programa de Pós-Graduação de Antropologia Social (PPGAS), Museu Nacional (UFRJ), sob supervisão dos professores Moacir Palmeira e José Sérgio Leite Lopes, da pesquisa: "Política, família e aparatos públicos: os modos de vida indígena e sua participação política na cidade", na linha de pesquisa "Antropologia do campesinato e das classes trabalhadoras", entre os anos de 2012 e 2018.

2 Observamos que o quesito língua falada se refere ao "nome da língua que a pessoa [indígena] falava no domicílio" (IBGE, 2010a, p. 41).

3 As explicações acerca dessa diferença, segundo Pery Teixeira, professor da Universidade Federal do Amazonas (UFAM), estão diretamente relacionadas à insuficiência da amostra do Censo de 2010. Isto, segundo ele, acarretou a queda vertiginosa de 4 mil indígenas, se comparado com o ano de 2000. 
entrevistas ${ }^{4}$ com algumas etnias e participar de reuniões durante o trabalho de campo desenvolvido nos meses de dezembro de 2014, março e maio de 2015, e fizemos ainda a devolução do resultado da pesquisa em dezembro de 2016 (PEREIRA, s. d.), cumprindo o acordo assumido com a Coordenação dos Povos Indígenas de Manaus e Entorno (COPIME). Durante esse período, realizamos duas oficinas para coleta de dados, gravação do documentário e a construção dos mapas de etnias e línguas faladas por bairros a partir da autoidentificação indígena. As referidas oficinas reuniram 120 indígenas de 20 etnias da cidade de Manaus e da região metropolitana. No Mapa 1, em tom mais escuro, os 10 bairros visitados durante o trabalho de campo.

Mapa 1 - Cidade de Manaus: bairros visitados

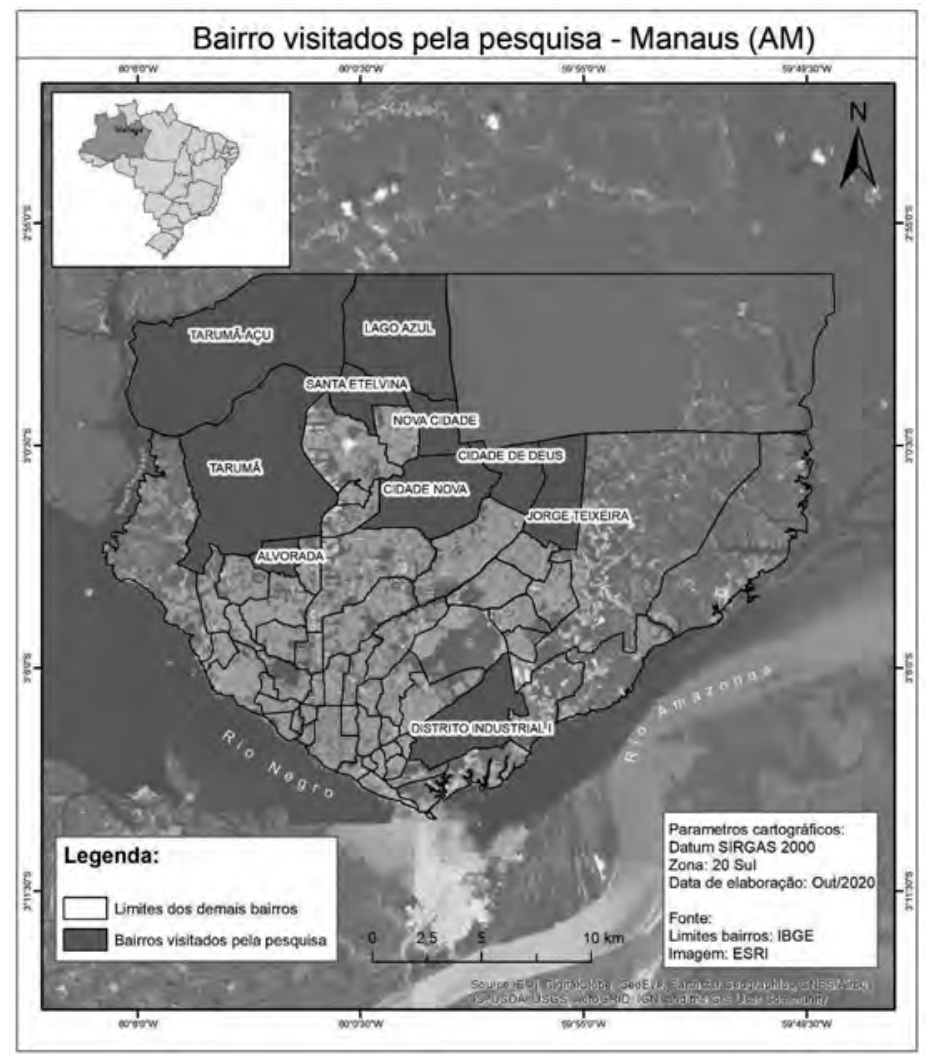

4 Realizamos 20 entrevistas com lideranças das etnias Sataré-Mawé, Tikuna, Kokama, Apurinã, Munduruku, Desano, Baré, Kaixana, Karapãna, Miranha, Maraguá e Tukano. Além delas, tomamos os depoimentos para o documentário "Indígenas na cidade de Manaus" e fizemos o levantamento fotográfico. Ainda fizemos a gravação de música indígena com o Instituto Mauati de Arte e Literatura Indígena, uma ONG multiétnica formada por poetas, compositores, cantores, contadores de história e escritores. Podemos citar entre os bairros visitados: Redenção, Lagoa Azul, Cidade de Deus, Tarumã, Tarumã-açu, Jorge Teixeira, Distrito Industrial, Nova Cidade e Santa Etelvina. 
A cartografia que elaboramos com integrantes da COPIME, em 2015, identificou 34 etnias em 51 bairros, sendo elas: Munduruku, Tikuna, Sateré-Mawé, Desana, Tukano, Miranha, Kaixana, Baré, Kokama, Apurinã, Tuyuka, Piratapuya, Kamaiura, Kambeba, Mura, Maraguá, Baniwa, Macuxi, Wanano, Tariano, Bará, Arara [do Aripuanã], Karapãna, Barasana, Anambé, Deni, Kanamari, Katukina, Kubeo, Kulina, Marubo, Paumari, Arara do Pará e Manchineri.

No que se refere à língua, os dados indicam 19 línguas faladas-Munduruku, Tikuna, Mawé, Mura, Desano, Tukano, Baré, Língua geral amazônica (Nhengatu), Piratapuya, Wanano, Apurinã, Tariano, Kaixana, Kokama, Karapãna, Tuyuka, Barasana, Baniwa e Kambeba - em 41 bairros.

Durante o trabalho de campo, observamos a precariedade das condições de vida desses indígenas em bairros visitados da periferia, que são destituídos dos serviços de saneamento e infraestrutura e insuficientes no atendimento em educação e saúde. Além disso, a moradia nas margens de igarapés, em áreas de encosta, em terrenos irregulares ou em ocupações sob a ameaça constante da ação policial ou de traficantes, bem como a violência e as medidas judiciais de reintegração de posse da terra são outros fatores cruciais.

Destacamos três áreas de ocupação não regularizadas juridicamente, nas quais se concentra grande quantidade de indígenas: o "Assentamento Povo Indígena do Sol Nascente", a "Comunidade Nações Indígenas" e o "Parque das Tribos", onde residem mais de 800 famílias de 20 etnias ${ }^{5}$. Estas ocupações se localizam em áreas públicas e privadas. No entanto, não se trata de ocupações exclusivamente indígenas, uma vez que estas representam porções menores de terra dentro de áreas mais abrangentes, onde os indígenas convivem com os não indígenas. Esses grupos indígenas apresentam uma reivindicação étnica que tem por objetivo a regularização da posse da terra e a retirada dos não indígenas que seriam reassentados em outro local. As dificuldades de moradia ampliam-se para além dessas três áreas referenciadas, visto existirem situações em que a concentração de indígenas é menor, posto que se multiplicam por vários bairros da cidade.

A vinda para a cidade exerce certa sedução sobre os indígenas. As expectativas remetem à melhoria das condições de vida, ao acesso à saúde e educação, ao mercado de trabalho e aos bens e serviços ofertados. Este é caso dos Tikuna que, nos anos de 1990, chegaram a Manaus. Hoje são 480 indígenas, distribuídos por 22 bairros. No bairro Cidade de Deus, eles estão desde 1997. Na comunidade Wotchimaücü são 17 famílias, totalizando 120 pessoas.

Kaixana, Mura, Apurinã, Tikuna, Sateré-Mawé, Kambeba, Piratapuya, Munduruku, Miranha, Macuxi, Arara, Kokama, Baré, Desano, Tukano, Tuyuka, Kamaiurá, Karapãna, Baniwa e Tariano. 
As mesmas explicações foram apresentadas por um dos integrantes da Associação Barayoá, no bairro Lagoa Azul, acerca do deslocamento aldeiacidade. No caso deles, o primeiro emprego de muitas famílias, no ano de 1995, foi na granja "Rei do Ovo". O não pagamento dos direitos trabalhistas por parte dos empregadores, ou seja, o não recolhimento das contribuições ao Instituto Nacional do Seguro Social (INSS) e o não pagamento do $13^{\circ}$ salário, levou a muitos pedidos de demissão. $\mathrm{O}$ valor alto das despesas com a vinda de barco e do aluguel levou muitas famílias a ocuparem as áreas livres, distantes do centro da cidade, onde construíram suas moradias. Isto deu origem, por exemplo, à comunidade de São João, depois do fechamento da granja.

Das famílias ligadas à associação, poucas são empregadas e algumas recebem o Bolsa Família, programa do governo federal. A "comunidade" São João não tem esgoto e os dejetos são jogados nas valas, as ruas são de chão batido, não há coleta de lixo, os igarapés do entorno estão poluídos e a água usada para abastecimento doméstico vem de um sistema do próprio bairro que os indígenas pagam $\mathrm{R} \$ 35,00$ (trinta e cinco reais) pelo fornecimento mensal. Ressalta-se ainda a precariedade da escola de educação infantil, do policiamento, do posto de saúde do bairro e do atendimento do transporte coletivo, caso alguém necessite se deslocar para outro local, principalmente em busca de atendimento médico.

Os diversos lugares visitados apresentam problemas comuns e a vida indígena na cidade de Manaus é marcada por processos de ressignificação. Isso implica tanto nos novos usos que dão ao espaço, quanto na sua renomeação, considerando aspectos como a etnicidade ${ }^{6}$ e a valorização de sua organização política enquanto povos indígenas. As denominações de ruas e das novas áreas habitadas com nomes indígenas são usuais, como forma de demarcar a sua territorialidade. Como exemplo, identificamos a rua Baré e a rua União dos Povos. Assim, o que ontem era local abandonado vira moradia, plantação de frutas, verduras, legumes, sementes e ervas medicinais. Os Kokama, no ramal do Brasileirinho, fazem esse tipo de produção para atender as necessidades de 90 famílias da etnia em um pequeno pedaço de terra. No bairro autorreferido como "Nações Indígenas" criam-se animais de pequeno porte; plantam-se mandioca, ervas medicinais e urucum. Este último serve para a pintura corporal que antecede rituais e atividades importantes e as sementes são usadas como matéria-prima do artesanato.

6 Assinalamos que o conceito de etnicidade "é definido como envolvendo relações entre coletividades no interior de sociedades envolventes, dominantes, culturalmente hegemônicas e onde tais coletividades vivem a situação de minorias étnicas, ou, ainda, de nacionalidades inseridas no espaço de um Estado-nação" (OLIVEIRA, 1978, p. 89). Dessa forma, para fins analíticos, o étnico se refere aos migrantes estrangeiros, aos indígenas e quilombolas presentes em cidades. 
Dessa forma, o espaço habitado e suas contradições resultam da prática de diferentes agentes orientados por uma "geografia das designações" (ALMEIDA, 1994, p. 32), o que, por sua vez, inclui os usos do lugar e o sentido a ele associado. Referimo-nos, pois, aos usos étnicos, assim como à construção da maloca, às danças e rituais, à pintura do corpo, aos cantos e ao aprender a língua, à produção do artesanato, às práticas agrícolas e alimentares, realizados por múltiplas etnias; bem como às hierarquias criadas por aqueles e aquelas que detêm certo prestígio frente à coletividade étnica: os caciques, as lideranças, os professores e os mais velhos. Neste sentido, Certeau (1994, p. 200) nos remete a uma "geografia de ações" ligada ao percurso, à trajetória, ao mapa mental que orienta as práticas. Essas duas perspectivas nos ajudam a enquadrar analiticamente o deslocamento indígena: da aldeia para a cidade e, na cidade, sempre em direção à periferia destituída de bens e serviços e onde a vida se realiza de forma precária.

Demarcar território e (re)significá-lo implica também no construto de objetos que façam parte de seu universo sociocultural, espacial e afetivo. A isso podemos creditar a presença da arquitetura indígena com seus traçados triangulares e circulares feitos de palha e caibro, amarrados com cipó.

O baixo nível de escolaridade e a falta de qualificação da mão de obra empurram os indígenas para atividades braçais na construção civil e no comércio; ao mercado informal (bicos) e ao desemprego ${ }^{7}$. No caso das empregadas domésticas, elas denunciam as situações de violência física, sexual e simbólica e falam sobre a humilhação, o preconceito e a discriminação vivida.

Longe de ser uma situação isolada, identificamos outros fatos que demonstram essa relação assimétrica entre índios e não índios. Os mais jovens passam por situações de constrangimento diante da população não indígena e os estigmas lançados que os fazem negar a sua origem étnica. E mesmo os moradores das áreas de ocupação, vindos do interior do estado do Amazonas, têm preconceito em relação aos indígenas. Somam-se a essas situações, aquelas que nos remetem ao processo de colonização e à catequização dos indígenas pelos padres de colégios católicos. No internato, os indígenas, por exemplo, que fossem pegos falando a língua nativa eram castigados, uma vez que o português era a língua oficial da escola.

\footnotetext{
No que se refere ao trabalho desenvolvido por eles, as experiências conhecidas e vividas fazem referência a artesanato, horta, seguranças, pedreiros, carpinteiros, domésticas, professores, motoristas, pintores, industriários nas fábricas da Zona Franca de Manaus, garis, serviços gerais, gerentes de loja, escritores, atores, músicos, marcheteiros, construção naval, guias turísticos, jogadores de futebol e professores de artes marciais. Um único médico da etnia Munduruku foi identificado, segundo informações repassadas por parentes da etnia, como sendo formado pela Universidade de Cuba.
} 
Ferir a autoestima do outro constitui uma estratégia daquele que está numa relação favorável de poder para demonstrar a sua superioridade, conforme tratam Elias e Scotson (2000). Assim, os rótulos negativos e os nomes depreciativos ilustram essa condição. Ou seja, falar a língua do branco, vestir suas indumentárias e adotar seu modo de vida correspondem a interiorizar suas "qualidades", bem como representa a possibilidade de ascender ao "mundo civilizado", segundo a perspectiva assimilacionista.

Tal situação é combatida pelos mais velhos, pais e mães que buscam a afirmação da identidade indígena, da organização em torno de associações e das lutas por políticas diferenciadas, do reaprender a língua nativa e os modos de vida dos antepassados e das famílias que ainda vivem nas aldeias, mesmo agora morando ou tendo nascido na cidade.

Pertencer a uma categoria étnica implica numa identidade básica por meio da qual o indivíduo se "reconhece, julga e é julgado" segundo as premissas dessa identidade. Identificar uma pessoa como pertencente ao mesmo grupo étnico significa dizer que ela compartilha dos mesmos "critérios de avaliação e julgamento". Assim, as fronteiras étnicas, segundo Barth, se referem aos critérios de pertença e aos demarcadores das diferenças dos códigos de valores distintivos nas relações interétnicas (BARTH, 2011, p. 196).

Diz um indígena Bará que mais do que aprender a língua na escola, a criança precisa viver a língua em casa e na família. Reclama que não se ensina a fazer comidas e bebidas apreciadas pelos indígenas, como quinhapira [uma caldeirada de peixe com pimenta], maniçoba, caxiri [bebida típica feita de banana e cará fermentados, mas pode ser de macaxeira e abacaxi], beiju [alimento feito da goma da mandioca], mingau e a cozinhar um peixe. Como se na cidade não se precisasse manter esses costumes praticados sistematicamente no "interior". Diz este indígena que "não há como se esconder que se é indígena dentro da sociedade". Ressaltamos que Bourdieu (2003, p. 83) afirma em suas análises que "o estigma étnico está inscrito de forma indelével, na tez e nos traços do rosto, e também no próprio nome".

Ao usar o termo "fricção interétnica", Oliveira (1972, p. 17) busca explicar a relação entre índios e não índios numa perspectiva sociológica, demonstrando as tensões envolvidas nessas situações, muitas vezes, destruidoras e desorganizadoras da vida indígena quando entra em contato com a sociedade nacional - violência do exército, invasão e expropriação de seus territórios por empresas madeireiras e de extração de seringa, enunciação do estereótipo contra os indígenas, propagação do medo por grupos econômicos interessados em seus territórios, castigos corporais, trabalho forçado e a ação catequista 
para transformá-los em mão de obra voluntária - que nada têm a ver com atos solidários e de alteridade entre os grupos tribais.

Esses fatos levam ao estabelecimento de regras que indicam, por exemplo, que durante as apresentações do grupo musical da associação Bayaroá não haja consumo de bebida alcoólica por nenhum de seus integrantes. Essa prevenção foi tomada para evitar o rótulo negativo que associa o indígena ao "alcoólatra". Até mesmo nas atividades internas da associação essa situação é observada.

Com a mesma preocupação, argumenta um Tikuna, que na escola é mais fácil falar em português. Daí advém a preocupação dos mais velhos com a "morte" da língua na cidade. Por essa razão é que surgiu a iniciativa de revitalização da língua Tikuna e as medidas preventivas de manter o vínculo com a aldeia. Esse deslocamento é visto como necessário para assegurar o contato com a língua materna em tempo que dura entre três meses a dois anos. Às vezes, os parentes vêm para a cidade ou as crianças vão à aldeia durante o período de férias e retornam quando as aulas recomeçam, num fluxo constante de idas e vindas. Inclusive, algumas famílias e etnias têm barracões na cidade ou cômodos na casa para receber os parentes oriundos da aldeia, que ficam na cidade durante certo período do ano e depois retornam para seu lugar de origem.

No plano da argumentação e da percepção indígena, os significantes "interior", "aldeia", "terra indígena", "rural" e "índio na base" fazem parte do universo vocabular para se referir à experiência pretérita ou àquele lugar de ida ou de vinda, em algum momento do ano.

\section{MODOS DE VIDA INDÍGENA E A RELAÇÃO ALDEIA-CIDADE/ CIDADE-ALDEIA}

O trabalho de campo nos propiciou encontros, visitas e conversas com muitas etnias. Numa delas, um Sateré-Mawé contou a experiência de seu filho que foi passar as férias escolares na aldeia e voltou dizendo que não queria mais ser indígena. Em sua justificativa de criança estava a explicação de que "índio anda muito", conforme relatou o pai sobre a conversa que teve com o filho. Assim, a vida na cidade serve de parâmetro comparativo que distancia as gerações. Especialmente, destaca-se a resistência daqueles nascidos na cidade, que têm uma condição indígena, bem diferente da de seus avós e pais - os indígenas de terceira geração. Os objetos da sociedade de consumo já fazem parte do seu cotidiano, não querem aprender a língua e negam a sua condição de indígena. Observamos que esses jovens parecem ser o elo frágil da relação, que distancia o indígena que 
vive na cidade do passado da aldeia ou da afirmação identitária e representam a ameaça de ruptura, caso nenhuma atitude seja tomada por parte dos mais velhos.

O casamento interétnico constitui outro fator de risco, uma vez que é tratado como elemento desagregador da cultura indígena na cidade. Disse-nos um Bará, sinalizando com preocupação, que já é comum a existência de filhos de mãe indígena e pai não indígena. Argumentando que mesmo adquirindo o Registro Administrativo de Nascimento Indígena (RANI) ${ }^{8}$, não se assumem como indígena, não praticam a língua e os costumes, nem participam das atividades da associação.

O surgimento da figura do "caboclo", resultante do casamento interétnico entre brancos e índios, implica em grandes tensões nessa relação, já que para o branco, o caboclo representa o índio "domesticado" e "amansado", submetido a uma situação de inferioridade. Isso tanto resulta, por um lado, no desprezo do branco para com ele, bem como cria a resistência tribal frente a essa forma de casamento, uma vez que os filhos advindos dessa relação são considerados "membros espúrios da comunidade tribal" (OLIVEIRA, 1972, p. 85).

O deslocamento aldeia-cidade ganha regularidade por meio das trajetórias individuais e familiares que veem a cidade como espaço de oportunidade e superação de muitas dificuldades enfrentadas na aldeia. Isso não deve ser entendido como uma iniciativa individual sem relação com o consentimento da parentela. Esse é o caso de um jovem Sateré-Mawé que foi para Manaus estudar na Escola Agrícola e esbarrou nas dificuldades em conciliar os estudos e suas carências financeiras e materiais, e como consequência o abandono da escola tornou-se inevitável. Contudo, apesar das adversidades, concluiu o ensino médio e já está cursando Turismo, na Universidade Federal do Amazonas (UFAM). Mesmo assim, as referências do passado sempre orientam as escolhas citadinas e as afirmações identitárias. Referimo-nos à vida na aldeia; ao convívio familiar; à caça de veado, paca, cutia, tatu, durante as noites com seu pai, exímio caçador; à pesca do tucunaré, traíra, cará, pacu, jacundá e arari, peixes fartos no rio nas proximidades da aldeia; à vida na roça, e ao plantio de cará, mandioca e banana. Esse jovem relata as habilidades desenvolvidas com a ajuda do

\footnotetext{
8 "O Registro Administrativo de Nascimento de Indígena (RANI) é um documento administrativo fornecido pela FUNAI, instituído pelo Estatuto do Índio, Lei no 6.001 de 19 de dezembro de 1973: 'O registro administrativo constituirá, quando couber, documento hábil para proceder ao registro civil do ato correspondente, admitido, na falta deste, como meio subsidiário de prova'. Em outras palavras, o RANI pode servir como documento para solicitar o registro civil. O registro do RANI é realizado em livros próprios por funcionários da FUNAI e para cada registro é emitido o documento correspondente, devidamente autenticado e assinado. Importante: o RANI é um documento administrativo e não substitui a certidão de nascimento" (FUNAI, 2020, p. 1).
} 
avô - como andar na floresta, utilizar os utensílios de caça, fazer fogo, pegar a caça e levar para a aldeia.

O meu pai era um bom caçador da noite. Ela caçava [...] paca, tatu, veado, e outras, né? Já o meu avô, o nosso avô, tive outro tipo de experiência. Ele tinha uma preocupação de levar nós pra mata pra aprender a sobreviver, né? O que ele fazia? Levava os netos, todos com uma carga: um com farinha, outro com água, outro com terçado, outro com machado, outro com fogo. Porque na aldeia o fogo é difícil. Então, ele acendia um tição de fogo e a gente passava pra não deixar aquele fogo apagar. Quando ele pedisse pra acender o cigarro dele tinha que tá aceso o fogo. E como isso a gente tinha uma responsabilidade pra não deixar esse fogo apagar. Aí acho que a atividade mais difícil era do fogo. Que não podia apagar, porque se apagasse já era, né? Aí então quando chegava no local fazia o fogo [...] pra fazer o assado, né? (Indígena Sateré-Mawé, Manaus-AM, dez. 2014).

Os aprendizados se relacionavam ao "sobreviver na mata", segundo a perspectiva de seu avô, que mais parecia brincadeira diante dos olhos da criançada. Essa sistematicidade da vida cotidiana e os aprendizados passados de geração em geração remetem à "Ciência do Concreto", conforme define Lévi-Strauss (1989, p. 31). Para o autor, o indígena tem uma grande capacidade de nomeação de animais, plantas e insetos e usa os frutos da floresta porque conhece e são uteis para a coletividade. O indígena "prova o fruto, cheira as folhas, quebra, examina e [...] observa o seu habitat [porque tem] [...] o senso agudo de observação" (LÉVISTRAUSS, 1989, p. 19). Isso configura, segundo esse autor, uma capacidade intelectual de experimentação de longa duração.

Esse Sateré fez referências à perda da prática ritual por conta da interferência das religiões católica e evangélica na cultura indígena. O "ritual da tucandeira", por exemplo, é criticado pelas religiões, mas para os indígenas ele é símbolo de saúde, conhecimento e o momento de passagem da infância para a idade adulta. A argumentação remete ainda à adoção de nome branco pelo indígena que chega à cidade, chamando atenção que o cartório de registro de nascimento se recusa a registrar o nome indígena, "tem que ser nome de branco", contesta ele. Assim, as mudanças se tornam inevitáveis: Turi (Icles), Arkitó (Barnabé), Aracamari (Osmar), Diacarapó (Deolinda) e Eiuketê (Dobertino).

No imaginário indígena, os mitos fornecem as explicações sobre a presença dos Sateré-Mawé no mundo, como as lendas do Porati e do Guaraná. A primeira trata de um remo mágico - o Porati -, que se refere à criação dos primeiros animais e dos homens, do bem e do mal; da busca do alimento Sateré e dos espíritos malignos. A segunda está relacionada à criação dos Sateré, filhos do Guaraná. Trata da presença de três irmãos no mundo, dois homens e uma 
mulher, que engravida de outro ser e de sua fuga do paraíso, já que os irmãos prometeram matar seu filho. Em decorrência disso, a armadilha foi montada e seu filho foi cortado em partes. Depois foi enterrado pela mãe que profetizou que ele seria uma grande liderança conhecida em todo mundo. Dele nasceram todos os animais e a primeira criança Sateré-Mawé - Uruará -, o filho do Guaraná e de onde descende essa etnia. Diz ele, que essa lenda é repassada pelos mais velhos aos mais jovens, para que nunca se esqueçam de onde vieram, já que do ponto de vista indígena, ela representa o conhecimento de sua história (Indígena SateréMawé, Manaus, dez. 2014).

Do livro Ugütaerü'ü y tikunaaarü, Cagü'üarünatchiga, Oregüarün'gü da Associação Comunidade Wotchimaücü Tikuna de Manaus, trazemos uma história infantil denominada "A samaumeira que escurecia o mundo":

No princípio tudo era escuro, sempre frio e sempre noite. Uma enorme samaumeira wotchine fechava o mundo e por isso não entrava claridade na terra. Yo’i e Ipi ficaram muito preocupados com essa situação, então, através de um buraquinho na árvore, os irmãos enxergaram uma preguiçareal que prendia lá no céu os galhos da samaumeira. Tentando derrubar a árvore, jogaram muitos e muitos caroços e assim criaram as estrelas. Mas não havia claridade, então Yo’i e Ipi ficaram pensando e decidiram convidar todos os animais da mata para ajudarem a derrubar a árvore. Mas nem um deles conseguiu, nem mesmo o pica-pau. Resolveram, então, oferecer a irmã Aicüna em casamento para quem jogasse formiga-defogo nos olhos da preguiça real. O quatipuru tentou, mas voltou no meio do caminho. Finalmente aquele quatipuruzinho bem pequeno, chamado Taine, conseguiu subir. Ele jogou as formigas e a preguiça soltou o céu. A árvore caiu e a luz apareceu. E cumprindo a promessa, os irmãos fizeram o casamento de Taine com Aicüna (ACW, 2007, p. 48).

As cosmologias indígenas se referem a saberes e mitos que explicam a presença do indígena no mundo. Dessa forma, envolvem as relações matrimoniais e de parentesco; a relação com a natureza, entre os clãs e sua classificação; além do processo de aprendizado. Não diz respeito somente ao presente, mas especialmente ao passado, e define a forma como veem o mundo, como se organizam socialmente e os modos de vida praticados (OLIVEIRA, 1972).

Isso nos leva a ressaltar os mecanismos que permitem aos indígenas manterem os laços sistemáticos com a aldeia e a afirmação de sua identidade étnica na cidade. Podemos fazer referência à concentração de famílias de uma ou de várias etnias num mesmo local de moradia ou bairro, sob a nomenclatura de "comunidade", bem como a formação das associações indígenas étnicas, multiétnicas - constituídas por várias etnias - e de gênero que têm por objetivos propiciar a prática de rituais, produzir o artesanato, praticar os hábitos alimentares, 
ensinar a língua materna ou agrupar as etnias na luta em torno das políticas diferenciadas. Diante disso, podemos afirmar que eles trazem um pouco da aldeia para a cidade e que o agrupamento das pessoas se constitui em uma estratégia para enfrentar as adversidades da vida citadina.

\section{ASSOCIAÇÕES ÉTNICAS, MULTIÉTNICAS E DE GÊNERO}

As organizações indígenas na cidade funcionam como espaço de articulação política das famílias e etnias, de práticas comuns materiais e simbólicas e de lutas identitárias e se constituem como interlocutoras dos órgãos governamentais. Este convívio é possibilitado por reuniões sistemáticas de cada etnia nas festividades das associações em que convidam os parentes para compartilharem dos rituais, nas atividades da Coordenação dos Povos Indígenas de Manaus e Entorno (COPIME) ou na mobilização coletiva na busca dos direitos indígenas, conforme trataremos com mais detalhes a seguir.

Nessas associações funcionam as "escolas indígenas", denominadas de "centros culturais". Nelas as crianças aprendem a língua materna, canto, dança, hábitos alimentares, rituais, pinturas e artesanato em horário diferente da escola do ensino regular. É o espaço de ressocialização das crianças e jovens nos modos de vida indígena e a reafirmação dos aprendizados pretéritos da aldeia na cidade. Esses centros estão localizados em associações indígenas, mas podem ser encontrados também em cômodos das residências, no quintal, na maloca ou em outro espaço improvisado para este fim.

Esta iniciativa remonta à década 1990 por meio de uma parceria das organizações indígenas - como por exemplo, Sateré-Mawé, Tikuna e Kokama - com a prefeitura, que hoje computam 11 experiências e atendem cerca de 300 alunos que, mesmo diante das dificuldades - a falta de merenda e de material didático e a precariedade das escolas para receber as crianças -, representam uma possibilidade de socialização dentro das formas de manifestações socioculturais indígenas.

Essas organizações constituem-se também em um espaço importante na produção do artesanato. O trabalho realizado resulta em bolsas, pulseiras, colares, brincos, redes, porta-joias, tapetes, cestinhas e gargantilhas, feitos de tucumã, jarina, inajá, palha, cipó, açaí, dentre outras matérias-primas, muitas vezes trazidas das aldeias, coletadas na cidade ou compradas de atravessadores. Muito desse trabalho é feito manualmente, mas existe uma experiência que usa maquinário na produção, como o caso dos Apurinã, do bairro Cidade de Deus, em uma área denominada de "Aliança com Deus", configurando uma exceção 
diante de um grande contingente que não tem equipamentos e nem apoio governamental para desenvolver suas atividades.

Esse grupo Apurinã faz a coleta da matéria-prima numa área florestal próxima ao lugar de moradia. No local, verificamos o armazenamento de sementes, os maquinários destinados à produção (lixas, furadeiras e cortadeiras) e a divisão do trabalho entre homens e mulheres da etnia, em um pequeno espaço coberto de plástico e sustentado por madeira, improvisado no fundo do quintal da residência.

Apesar de todo empenho indígena nessa atividade, estes reclamam da falta de matéria-prima e de apoio do governo, da presença de atravessadores, concorrentes que compram mais barato e em quantidade diretamente dos indígenas para venderem mais caro em lojas dos shoppings centers e da ausência de uma área verde na cidade destinada à coleta de insumos para a produção do artesanato. As existentes estão sob a guarda do Instituto Brasileiro do Meio Ambiente e dos Recursos Naturais Renováveis (IBAMA), Exército e universidades e são inacessíveis aos indígenas que vivem nas proximidades e que poderiam usufruir de sementes, caroços, árvores e raízes. Para buscar no “interior” há gastos com a passagem de barco e falta dinheiro para comprar a matéria-prima.

Essa atividade é a fonte de renda principal da família ou complementar ao salário do marido. Também permite às mulheres trabalharem em casa e cuidar dos filhos mais novos, levá-los à escola ou ao médico, já que se trata de um trabalho desenvolvido majoritariamente por elas. Inclusive, foi criada uma associação multiétnica com este fim. Trata-se da Associação de Mulheres Artesãs Indígenas do Alto Rio Negro (AMARN) - Numiá Kura que, na língua Tukano, quer dizer "grupo de mulheres" -, composta por 64 mulheres de 10 etnias, 35 delas trabalhando diretamente com o artesanato. Outro exemplo é a Organização das Mulheres Indígenas Sateré-Mawé de Manaus (OMISM), no bairro da Redenção.

Essa produção, segundo a perspectiva indígena, vai muito além de um produto para vender no mercado, uma vez que esta é a expressão da cultura, da identidade e dos modos de vida indígena, como nos afirmou um indígena Bará:

Pra mim, eu sempre digo, o artesanato não é somente produto mercantil. Pra nós é vida. É cultura. Ela é linguística. Ela é uma identidade que nos afirma através desse artesanato bonito com grafismo, com simbologia, com pintura. Ela expressa uma riqueza da humanidade. Não é somente do povo indígena, mas ela é da humanidade (Indígena Bará, Manaus-AM, dez. 2014).

Por essa razão, quando um indígena produz o artesanato, ele está incorporando ao objeto construído seu modo de vida e sua visão de mundo. 
Assim, esse objeto traz significados e significantes maiores do que o valor monetário pago em sua aquisição. Dito de outra forma, o comprador do colar, por exemplo, o adquire como um adorno e ganha um significante maior que o valor pago no momento da compra. Contudo, isso não é claro para quem o compra, salvo tenha conhecimento prévio sobre a relação que os indígenas estabelecem com a natureza - as sementes, a floresta, os animais e a natureza morta (resíduos de vegetais que fazem parte da matéria-prima de seu trabalho). Uma pele de onça, uma pena de arara azul ou um dente de animal podem representar um valor subjetivo inestimável, muitas vezes desconsiderado no momento da compra.

O formato de organização política indígena na cidade é diverso. Também identificamos a organização não governamental Instituto Mauati de Arte e Literatura Indígena, com atuação estadual e que reúne artistas indígenas (cantores, artistas plásticos, escritores, ilustradores, músicos e contadores de história) das etnias Sateré-Mawé, Maraguá, Tikuna, Tukano, Macuxi, Baniwa, Munduruku, Tuyuka, Barasana, Desano e Mura. Entrevistamos um dos escritores da etnia Maraguá que nos relatou sobre várias obras publicadas por uma editora local que valoriza a literatura indígena e colabora na difusão de sua visão de mundo por meio das lendas e mitos que ganham forma de "contação" de história.

Já a Associação de Expressão Natural do Grupo Bayaroá (AENGBA), que na língua nativa quer dizer "mestre de dança" ou "mestre cerimonial", foi criada no ano de 1998 e é onde funciona uma escola indígena desde 2012. Essa escola tem a finalidade de trabalhar o fortalecimento da cultura, por meio da dança, dos ritos, da pintura, do aprendizado da língua e da escrita. As três linhas de trabalho do grupo Bayaroá estão relacionadas a cultura, educação e artesanato. O quadro de associados é formado por 22 famílias (86 pessoas) de nove etnias (Bará, Baré, Desano, Itano, Karapãna, Piratapuia, Tariano, Tukano e Tuyuka) que falam a língua Tukano. Trata-se de uma associação multiétnica. Falar desse grupo de danças tradicionais remete às famílias vindas do Alto Rio Negro, da região da Cabeça do Cachorro, no município de São Gabriel da Cachoeira, no oeste do estado do Amazonas.

Esse conjunto de procedimentos, práticas e condutas de afirmação identitária, que são motivo de orgulho indígena, funcionam como "indicadores ou símbolos de pertencimento étnico", conforme se refere Mitchell (2010, p. 397). Dessa forma, supõe-se que quanto maior for o uso do repertório indígena na cidade, maior será o seu reconhecimento pelos pares e por aqueles que ainda vivem na aldeia, mas que regularmente visitam os parentes que moram no contexto urbano. 
A Coordenação dos Povos Indígena de Manaus e Entorno (COPIME) foi criada em 2011 e funciona com "a mãe das associações", conforme afirmou seu coordenador da etnia Sateré-Mawé. Em torno dela estão associadas 47 organizações indígenas da cidade de Manaus e 12 do entorno (cidades integrantes da região metropolitana), representando aproximadamente 3 mil indígenas. Ela tem um papel de grande relevância organizativa em torno da luta por políticas específicas e diferenciadas, além de servir de espaço de encontro e diálogo entre as diferentes etnias e suas organizações representativas não só da cidade de Manaus, mas da região metropolitana, o que ainda inclui os municípios de Rio Preto da Eva, Itacoatiara, Presidente Figueiredo, Iranduba, Manacapuru, Novo Airão e Careiro da Várzea que, estatutariamente, vêm sendo chamado por ela de "entorno".

As associações étnicas, multiétnicas e de gênero têm uma ação mais pontual, específica e localizada. A COPIME, por sua vez, aparece como a organização do encontro desses pedidos, canalizando anseios, aspirações, bem como demandas em torno de um projeto coletivo identitário mais amplo. Ou seja, as políticas diferenciadas para os indígenas na cidade de Manaus e seu entorno. Também observamos simultaneamente as articulações políticas realizadas por ela. São propostas de ordem estadual, mesorregional e nacional em torno da luta contra o Projeto de Emenda Constitucional: a PEC 215. Esta representa uma grande ameaça para a demarcação das terras indígenas, uma vez que transfere das "mãos" do governo federal para o Legislativo essa prerrogativa. Há também o projeto de lei em tramitação no Congresso Nacional que autoriza a mineração em terras indígenas. Em destaque ainda a proximidade de entidades mais gerais como a Coordenação das Organizações Indígenas da Amazônia Brasileira (COIAB), Federação das Organizações Indígenas do Alto Rio Negro (FOIRN), Articulação dos Povos Indígenas do Brasil (APIB) e a participação em manifestações nacionais em torno da pauta indígena unitária. Isto remete à luta simultânea em diferentes escalas de ação e à articulação de cooperação com universidades, entidades religiosas e organizações não governamentais.

Organizar os indígenas, reunir as lideranças, identificar os problemas, planejar as atividades, formar comissões, negociar com os governantes, realizar audiências públicas e seminários, ocupar a FUNAI e apresentar as reivindicações estão entre os repertórios acionados à ação política, bem como aos pedidos de preparação política dos agentes públicos para lidar com as demandas identitárias, uma vez que o "indígena não se encaixa na política do branco", conforme relatou um indígena da etnia Sateré-Mawé. Isso equivale dizer que estes devem saber quem são os indígenas, quais são as suas práticas culturais e como vivem na 
aldeia para identificar a melhor forma de diálogo e a política mais adequada a eles direcionada. Isto não está relacionado somente ao passado, mas exige entender e respeitar as modificações socioculturais por que passam os indígenas na cidade. Diz Pacheco de Oliveira que os indígenas:

Estão adaptando sua cultura a novas condições de vida, estão fazendo exercícios criativos [...] produzindo relações novas [...]. O índio é um produtor de cultura. $\mathrm{O}$ índio vive a partir daquela cultura que ele elabora e constrói de acordo com estratégias que ele tem como as mais adequadas a si e seus parentes, aqueles que estão associados a ele [...] (Pacheco de Oliveira, Rio de Janeiro-RJ, jun. 2016).

O que nos leva a perceber que se trata do presente, constantemente atualizado, e não apenas do passado indígena. Os processos identitários, longe de representarem isolamento, guardam relação com atos políticos de afirmação de "uma identidade étnica diferenciadora" e com a circulação dinâmica dos significados. As afinidades culturais e linguísticas e os vínculos afetivos e históricos estão em relação ou em confrontação com membros ou grupos diferentes, como as organizações religiosas e as agências estatais ou dizem respeito à situação dos grupos étnicos dentro do Estado-nação, o que implica, por sua vez, em um processo de reorganização sociocultural em proporções mais amplas (PACHECO DE OLIVEIRA, 1998, p. 55).

\section{CONCLUSÃO}

A cidade tratada em nossa análise diz respeito ao espaço de "coexistência" de múltiplas formas de viver em sociedade. Fernandes (1979) propõe em sua formulação que o campesinato - o grande contingente da mão de obra usada na industrialização do país - mudava para a cidade levando consigo o seu modo de vida rural. No caso dos indígenas da cidade de Manaus, analiticamente seguimos a mesma perspectiva admitindo que há um processo de integração sem assimilação (OLIVEIRA, 1968). Ou seja, eles vão para a cidade, mas não "abrem mão" de continuarem sendo indígenas. Observamos empiricamente que o repertório apreendido na aldeia é sempre acionado em situações que tornam possível tal condição. Isso nos remete à "população translocal", conforme define Sahlins (1997, p. 113). Isto é, aquela capaz de habitar vários mundos como parte integrante de uma totalidade sociocultural. O que nos leva, por sua vez, a supor que os híbridos culturais (CANCLINI, 2011) são tolerados: vestir-se como branco, falar sua língua e até adotar o seu padrão construtivo. Contudo, as recusas identitárias não serão admitidas. 
Dessa forma, nos afastamos das proposições, como as de Redfield (1947), que opõem aldeia e cidade, urbano e rural, ou de afirmações cristalizadas no senso comum que defendem que o indígena na cidade perde a identidade, porque ocorreria a desagregação cultural ou a aculturação, conforme assinala Nunes (2010). O que vimos pelo estudo de caso é justamente o contrário. Aqui não nos referimos ao índio "genérico", porque os indígenas são de múltiplas etnias, falam muitas línguas, mantêm diversas práticas rituais, alimentares e arquitetônicas, se organizam politicamente e lutam por políticas diferenciadas nas áreas de saúde, educação, moradia e reivindicam acesso à universidade e ao mercado de trabalho. Também mantêm laços fortes com o lugar de origem em visitas sistemáticas entre parentes, em deslocamentos que têm como fim estar ora na cidade, ora na aldeia.

Mas não podemos deixar de considerar o elo frágil dessa relação - os jovens indígenas nascidos na cidade - que, muitas vezes, negam serem indígenas por conta do preconceito dos não indígenas em relação ao pertencimento étnico, quando assumido publicamente. Por várias vezes, durante as entrevistas essa foi uma preocupação de pais e mães acerca dessa situação, apontando como solução a intensificação da convivência com os parentes, a prática da língua e dos costumes, além da participação nos eventos da associação indígena.

Assim, não nos referimos a eles como "índios citadinos", "desaldeados", "destribalizados", "não índios" ou qualquer outro termo classificatório ou depreciativo que lhes tire a possibilidade e o direito de afirmar e reivindicar o seu pertencimento étnico, por entender que se trata do caráter próprio das novas energias sociais emergentes, que reinventam e atualizam as formas de viver e de se (re)produzir, conforme trata Ribeiro (2012). E, dessa forma, questionam o viver na cidade, o perfil das políticas públicas e os estudos acadêmicos que explicam a vida urbana e a forma de "representar" a cidade. Do mesmo modo, questionam a forma como são vistos pela sociedade nacional. Ou seja, o lugar do indígena como sendo a aldeia, a floresta e o rural, andando nu, caçando, pescando, plantando e colhendo frutos, embora isso exista, como uma das dimensões na qual a vida social se realiza. Isto remete tanto ao imaginário social como aos parâmetros de classificação e à sua naturalização. Assim, o indígena na cidade é tido, pelo pensamento dominante, como algo fora do lugar, um intruso ou forasteiro.

Tomando como referência Bourdieu (2007), afirmamos que é no campo da luta política que se dá a luta pelo reconhecimento identitário e a apresentação de demandas e proposições. O fazer-se conhecer frente à opinião pública, agências governamentais e instituições sociais tem por objetivo tornar legítimas as suas reivindicações - isso do ponto de vista prático e político vem no sentido de sair 
da "invisibilidade" e subverter o poder dominante que os exclui. A denominação das ruas e os assentamentos onde moram com nomes indígenas, a formação dos grupos musicais, a publicação de livros, a produção e venda do artesanato, a sua aparição pública por meio de suas organizações são situações ilustrativas dessa busca por visibilidade. Assim, procuram se posicionar como agentes legítimos e aptos a conquistarem direitos sociais e políticas públicas de caráter étnico.

Considerando o contexto mais amplo da questão indígena, destacamos que o avanço das atividades econômicas de grande impacto sobre as áreas indígenas, como mineração, hidrelétricas, soja, exploração ilegal de madeira, construção de estradas e grilagem de terra acabam por empurrá-los para as periferias das cidades. Assim, podemos pensá-los como um "novo" fenômeno da urbanização brasileira e não apenas como um movimento residual, pendular e temporário.

A cidade praticada (CERTEAU, 1994) mostra a sua natureza múltipla, diversa e desigual indo além das formulações generalistas e homogeneizadoras que precisam ser consideradas pelas agências e políticas governamentais e pelo campo dos estudos urbanos para que se possa inscrever no âmbito das questões urbanas a presença indígena em cidades brasileiras de forma a iluminar a reflexão, tomando por base o pertencimento étnico.

\section{REFERÊNCIAS}

ACW. Associação Comunidade Wotchimaücü: projeto de revitalização da língua e cultura Tikuna em Manaus. Manaus: ACW, 2007.

ALMEIDA, A. Carajás: a guerra dos mapas. Belém: Falangola, 1994.

BAINES, S. G. As chamadas aldeias urbanas ou índios na cidade. Revista Brasil Indígena, Brasília, DF, v. 1, n. 7, p. 15-17, nov./dez. 2001. Disponível em: http:/ / www.funai.gov.br/ultimas/artigos/revista_7.htm\#001. Acesso em: 12 out. 2020.

BARTH, F. Grupos étnicos e suas fronteiras. In: POUTIGNAT, P., STREIFFFENART, J. (org.). Teorias da etnicidade: seguido de grupos étnicos e suas fronteiras de Fredrik Barth. São Paulo: UNESP, 2011. p. 185-227.

BOURDiEU, P. A miséria do mundo. Petrópolis: Vozes, 2003.

BOURDIEU, P. Meditações pascalianas. Rio de Janeiro: Bertrand Brasil, 2007. CANCLINI, N. Culturas híbridas. São Paulo: EDUSP, 2011.

CERTEAU, M. de. A invenção do cotidiano: artes do fazer. Petrópolis: Vozes, 1994. 
ELIAS, N.; SCOTSON, J. L. Os estabelecidos e os outsiders: sociologia das relações de poder a partir de uma pequena comunidade. Rio de Janeiro: Zahar, 2000.

FERNANDES, F. Mudanças sociais no Brasil. São Paulo: DIFEL, 1979.

FUNAI. Registro Administrativo de Nascimento de Indígena - RANI. FUNAI, Brasília, DF, s. d. http://www.funai.gov.br/index.php/docb/registroadministrativo-de-nascimento-de-indigena-rani. Acesso em: 02 mar. 2015.

IBGE. Censo Demográfico 2010: características gerais dos indígenas. IBGE, Rio de Janeiro, 2010a. Disponível em: http://www.ibge.gov.br. Acesso em: 10 abr. 2015.

IBGE. Censo Demográfico 2010. IBGE, Rio de Janeiro, 2010b. Disponível em: http://www.ibge.gov.br. Acesso em: 04 abr. 2015.

LÉVI-STRAUSS, C. O pensamento selvagem. Campinas: Papirus, 1989.

MITCHELL, J. C. A dança kalela: aspectos das relações sociais entre africanos urbanizados na Rodésia do Norte. In: FELDMAN-BIANCO, B. (org.). Antropologia das sociedades contemporâneas: métodos. São Paulo: UNESP, 2010. p. 365-436.

NUNES, E. S. Aldeias urbanas ou cidades indígenas? Reflexões sobre índios e cidades. Espaço Ameríndio, Porto Alegre, v. 4, n. 1, p. 9-30, jan./jun. 2010.

OLIVEIRA, R. C. Urbanização e tribalismo: a integração dos índios Terêna numa sociedade de classes. Rio de Janeiro: Zahar, 1968.

OLIVEIRA, R. C. O índio no mundo dos brancos. São Paulo: Pioneira, 1972.

OLIVEIRA, R. C. Sociologia do Brasil indígena. Brasília: UNB, 1978.

PACHECO DE OLIVEIRA, J. Uma etnologia dos “índios misturados"? Situação colonial, territorialização e fluxos culturais. Mana, Rio de Janeiro, v. 4, n. 1, p. 47-77, 1998.

PACHECO DE OLIVEIRA, J. O nascimento do Brasil e outros ensaios: "pacificação", regime tutelar e outros ensaios. Rio de Janeiro: Contra Capa, 2016.

PEREIRA, J. C. M. Início. Indígenas nas cidades amazônicas, [S. l.], s. d. Disponível em: https://www.indigenasemcidades.com/. Acesso em: 12 out. 2020.

REDFIELD, R. The folk society. The American Journal of Sociology, Chicago, v. 52, n. 4, p. 293-308, Jan. 1947. Disponível em: http://www.jstor.org. Acesso em: 06 set. 2009. 
RIBEIRO, A. C. T. Por uma sociologia do presente: ação, técnica e espaço. Rio de Janeiro: Letra Capital, 2012.

SAHLINS, M. O "pessimismo sentimental” e a experiência etnográfica: porque a cultura não é um "objeto” em via de extinção (parte II). Mana, Rio de Janeiro, v. 3, n. 2, p.103-150, 1997.

SANTOS, B. S. A globalização e as ciências sociais. São Paulo: Cortez, 2002.

\section{ENTREVISTAS}

01- Sateré-Mawé, 32 anos. Coordenação dos Povos Indígenas de Manaus e Entorno (COPIME). Entrevista concedida a José Carlos Matos Pereira, Manaus (AM), 13 dez. 2014.

02- Kokama, 41 anos. Professor. Entrevista concedida a José Carlos Matos Pereira, Manaus (AM), 18 dez. 2014.

03- Apurinã, 48 anos. Artesão. Entrevista concedida a José Carlos Matos Pereira, Manaus (AM), 15 dez. 2014.

04- Tukano, 28 anos. Aldeia Beija-Flor. Entrevista concedida a José Carlos Matos Pereira, Rio Preto da Eva (AM), 13 dez. 2014.

05- Tikuna, 47 anos. Cacique. Associação Comunidade Wotchimaücü Tikuna de Manaus. Entrevista concedida a José Carlos Matos Pereira, Manaus (AM), 8 dez. 2014.

06- Bará, 38 anos. Professor. Associação de Expressão Natural do Grupo Bayaroá (AENGBA). Entrevista concedida a José Carlos Matos Pereira, Manaus (AM), 12 dez. 2014.

07- Kaixana, 33 anos. Cacique. Assentamento Povo Indígena do Sol Nascente. Entrevista concedida a José Carlos Matos Pereira, Manaus (AM), 11mar. 2015.

08- Desana, 65 anos. Artesã. Associação de Mulheres Artesãs Indígenas do Alto Rio Negro (AMARN). Entrevista concedida a José Carlos Matos Pereira, Manaus (AM), 12 mar. 2015.

09- Maraguá, 37 anos. Escritor. Entrevista concedida a José Carlos Matos Pereira, Manaus (AM), 11 mar. 2015.

10- PACHECO DE OLIVEIRA, J. Entrevista concedida a José Carlos Matos Pereira, Rio de Janeiro (RJ), 11 abr. 2016.

Texto submetido à Revista em 21.02.2020

Aceito para publicação em 01.10.2020 
